\title{
Projections from the brain to the spinal cord in the mouse
}

Huazheng Liang ${ }^{1,2}$, George Paxinos ${ }^{1,2}$, Charles Watson ${ }^{1,3}$

1. Neuroscience Research Australia, NSW, 2031, Australia

2. School of Medical Science, The University of New South Wales, NSW, 2052, Australia

3. Faculty of Health Sciences, Curtin University, WA, 6845, Australia

Corresponding author: Charles Watson

Curtin University, Shenton Park Health Research Campus, GPO Box U1987, Perth, WA 6845, Australia. Phone: +61892661640 Fax: +61 892661650 .

E-mail address: c.watson@curtin.edu.au

\begin{abstract}
The cells that project from the brain to the spinal cord have previously been mapped in a wide range of mammalian species, but have not been comprehensively studied in the mouse. We have mapped these cells in the mouse using retrograde tracing after large unilateral Fluoro-Gold (FG) and horseradish peroxidase (HRP) injections in the $\mathrm{C} 1$ and $\mathrm{C} 2$ spinal cord segments. We have identified over 30 cell groups that project to the spinal cord, and have confirmed that the pattern of major projections from the cortex, diencephalon, midbrain, and hindbrain in the mouse is typically mammalian, and very similar to that found in the rat. However, we report two novel findings: we found labeled neurons in the precuneiform area (an area which has been associated with the midbrain locomotor center in other species), and the epirubrospinal nucleus. We also found labeled cells in the medial division of central nucleus of the amygdala in a small number of cases. Our findings should be of value to researchers engaged in evaluating the impact of spinal cord injury and other spinal cord pathologies on the centers which give rise to descending pathways.
\end{abstract}

Key words: descending spinal tracts, HRP, FG, retrograde tracing, precuneiform area, spinal cord injury.

\section{Introduction}

Pathways from the brain to the spinal cord in mammals play an important role in the initiation of movements of the limbs and trunk, including grasping, locomotion, respiration, and posture maintenance. The origin of these pathways has been studied in a wide variety of mammals. The best known centers that give origin to these pathways are the cerebral cortex (Miller 1987; Nudo and Masterton 1988; 1990; Galea and Darian-Smith 1994), the red nucleus (Pompeiano and Brodal 1957; Nyberg-Hansen and Brodal 1964; Carlton et al. 1985; Xu and Martin 1989; Kuchler et al. 2002 ), the brainstem reticular formation (Torvik and Brodal 1957; Nyberg-Hansen 1965; Peterson et al. 1975; Basbaum and Fields 1979; Nordlander et al. 1985; Sirkin and Feng 1987; Cruce et al. 1999; Satoda et al. 2002 ), and the vestibular nuclei (Peterson and Coulter 1977; Hayes and Rustioni 1981; Kimmel et al. 1982; Leong et al. 1984; Nudo and Masterton 1988; Masson et al. 1991; Wada et al. 1993; Lakke 1997 ). Apart from these well known centers of origin of the descending tracts, there are a large number of other nuclei that are labeled in retrograde tracing studies following spinal cord injections. These include the paraventricular nucleus (Berk and Finkelstein 1983; Okado and Oppenheim 1985; Kunzle 1992), the medial and interposed cerebellar nuclei (Med, IntP) (Bangma et al. 1984; Leong et al. 1984; Gross and Oppenheim 1985; Nudo and Masterton 1988; Sanchez-Camacho et al. 2001a), and the spinal trigeminal nucleus (Burton and Loewy 1977; Leong et al. 1984; Diagne et al. 2006). The relative size of these spinally projecting cell groups varies between species (Nudo and Masterton 1988).

There have been a few studies on the centers that give rise to the descending pathways in the mouse (Sbriccoli et al. 1995; Carretta et al. 2001; Tsukamoto et al. 2003). However, none of these studies attempted comprehensive description of the centers which give rise to the descending pathways. We believe there is a need for comprehensive baseline study which maps the cells of origin of these descending pathways to the spinal cord in the mouse. This will help other studies on the assessment of recovery after experimental spinal cord injuries. We have therefore attempted to reveal the spinal projecting neuron groups in the mouse by injecting retrograde tracers HRP and FG into the upper cervical spinal segments in a large series of mice.

\section{Materials and Methods}

\section{Animals}

C57/BL6 mice (10-12 weeks old, weight 25-30g) were used for this study. Mice were obtained from the Animal Resource Center of Western Australia. Large injections of retrograde tracer were made into upper cervical cord segments. The procedure was approved by the Animal Care and Ethics Committee of the University of New South Wales (07/108B, 08/48B). 


\section{Injection of retrograde tracer}

Mice were anaesthesized with an intraperitoneal injection of ketamine $(67 \mathrm{mg} / \mathrm{kg})$ and xylazine $(10 \mathrm{mg} / \mathrm{kg})$. They were then mounted in a mouse stereotaxic head holder (Kopf Instruments). A $5 \mu$ l Hamilton syringe was mounted on a micromanipulator for spinal cord injection. The mouse adaptor was adjusted for optimal exposure of the upper cervical vertebrae. The first and second cervical spinal cord segments were exposed by $\mathrm{C} 2$ laminectomy. The dura on the right side was incised with the tip of a $29 \mathrm{G}$ needle and the $5 \mu$ l Hamilton syringe was driven through this opening. An injection of 20-40nl tracer solution was made through multiple punctures into the right side of the spinal cord and the syringe was left in place for 10 minutes following the injection. Fluoro-Gold (Fluorochrome, Denver, Co, USA) was diluted to 5\% with distilled water and horseradish peroxidase (HRP, Sigma, type VI) was diluted to $30 \%$ with distilled water. In 12 cases HRP was injected, and in 18 cases FG was used. A control group of mice received normal saline injections into the spinal cord (3 cases each) and tracer injections into the cistern magna (3 cases each). The soft tissue and the skin were sutured and tetracycline was sprayed over the incision. Tamgesic (buprenorphine) was injected subcutaneously to relieve pain for two days after surgery.

\section{Tissue preparation}

After a period ranging from 48 to 96 hours, mice were anesthetized with a lethal dose of pentobarbitone sodium $(0.1 \mathrm{ml}, 200 \mathrm{mg} / \mathrm{ml})$ and perfused through the left ventricle, first with $60 \mathrm{ml}$ of $0.9 \%$ normal saline with heparin (Sigma, 150IU/mouse), followed by $80 \mathrm{ml}$ of $4 \%$ paraformaldehyde (Sigma) in $0.1 \mathrm{M}$ phosphate buffer (PB, $\mathrm{pH}$ 7.4 ), and then $80 \mathrm{ml}$ of $10 \%$ sucrose. The brain and cervical spinal cord were removed and postfixed in $4 \%$ paraformaldehyde for two hours at $4^{\circ} \mathrm{C}$, followed by cryoprotection in $30 \%$ sucrose in $0.1 \mathrm{M}$ PB solution (pH 7.4) overnight at $4^{\circ} \mathrm{C}$. Serial sagittal or coronal sections of the whole brain were cut at $40 \mu \mathrm{m}$ thickness using a cryostat. Coronal sections (40um) of the C1-C4 spinal cord segments were also cut using the cryostat. In cases of HRP injection, sections were directly mounted onto gelatinized slides and dried for more than 2 hours at room temperature, then stained by 3,3',5,5'-tetramethylbenzidine (TMB) (Mesulam 1978). In the case of FG, sections were mounted onto gelatinized slides, coverslipped with the anti-fade fluorescent mounting medium (Dako). HRP and Nissl sections were photographed with a Spot Insight camera mounted on an Olympus Provis microscope. FG labeled sections were examined with an Olympus fluorescence microscope equipped with a Zeiss Axio camera.

\section{Mapping}

Labeled neurons of all sections were analysed and mapped onto templates taken from the mouse brain atlas of Franklin and Paxinos (2008). The names and abbreviations of neuronal groups are those of Paxinos and Watson (2007) (See abbreviations in Table. 1). The mapping of labeled cells was assisted by reference to adjacent Nissl stained sections.

\section{Cell counting}

The labeled neurons were counted in two cases. The cases chosen were those that seemed to have the greatest number of labeled neurons in most areas. Labeled neurons were counted in every seventh section. The cells were counted with a Nikon Eclipse 80i microscope attached to an Optronics camera (Goleta, CA). which was in turn connected to a Dell Precision T3500 workstation using Stereoinvestigator software (MicroBrightfield, Williston, VT). The major boundaries of the section were drawn at $2 \times$ magnification, and labeled neurons were identified at $10 \times$ magnification. Each labeled cell was marked by a dot on the drawing. Labeled cells were identified on the basis that they contained a nucleus. In many cases a nucleolus was seen, but no attempt was make to ensure that each counted cell contained a nucleolus. For this reason, the counts should be considered to be general estimates of labelled neuron numbers. They are obviously not definitive counts.

\section{Results}

Both HRP and FG injections labeled cells in a wide range of brain regions. For the FG injections, different survival times were tried, but there was no significant increase in the number of labeled cells in the motor cortex after 96 hours survival. We therefore chose 96 hours as the survival time for the majority of the FG experiments For the HRP injections, the survival time was 48 hours. While both HRP and FG techniques labeled cells in the same areas, the intensity of signal was greater with FG injections. For this reason, we have principally used the FG data for the analysis reported here. A typical injection site is shown in the lower right corner of Fig.1. The estimates of the number of labeled cells in each region are listed in Table. 2.

\section{Cerebral cortex}

Labeled neurons were found in the primary and secondary motor cortex (M1, M2) (Fig. 1, 2, 16, 17, 18), and in 
the limb area (S1FL, S1HL), trunk area (S1Tr), shoulder area (S1Sh), and the dysgranular zone (S1DZ) of the primary somatosensory cortex (S1) on the contralateral side. Labeled neurons were also seen in the secondary somatosensory cortex (S2) on the contralateral side (Fig. 1, 2, 3, 18). The barrel field (S1BF) and upper lip (S1ULp) regions of the primary somatosensory cortex contained no labeled cells. The labeled cortical neurons were almost all pyramidal neurons in layer 5 and 6, with tear-shaped cell soma and long dendrites extending towards the pial surface. Labeled neurons were more plentiful in the motor cortex than in the somatosensory cortex. In M1, M2, and S1, the labeled neurons were arranged in three or more layers. In S2, only one or two layers of labeled neurons were observed. A small number of labeled neurons were present in the same motor and somatosensory cortical areas of the ipsilateral side.

\section{Amygdala and bed nucleus of stria terminalis}

In two cases, a small number of lightly labeled neurons were seen in the central part of the extended amygdala (EAC), the medial division of the central amygloid nucleus (CeM), and the anterior basolateral amygdaloid nucleus (BLA) on the ipsilateral side (Fig. 2, 3, 18). In one case, a few labeled neurons were found in the posterolateral part of the medial division of the bed nucleus of stria terminalis (STMPL). These neurons were in a line parallel to fibers of the internal capsule (ic) (Fig. 1).

\section{Diencephalic nuclei}

At the coronal level of dorsomedial hypothalamic nucleus (DM), the caudal part of the paraxiphoid nucleus (PaXi) contained one or two labeled neurons in each section (Fig. 3). A few cells in the subparafascicular thalamic nucleus (SPF) (Fig. 4) were labeled, but they were not as strongly labeled as those in the nucleus of dorsal zona incerta (ZID) (Fig. 3, 4, 18) at the same level. Some labeled neurons were identified in $\mathrm{H}$ field of Forel $(\mathrm{H})($ Fig. 4, 16, 17) and there were labeled neurons present in the caudal part of the parafascicular nucleus (PF) of the ipsilateral side (Fig. 4, 16). More caudally, a dense cluster of neurons was found in an area which seemed to be either the lithoid nucleus (Lth) or the periaqueductal gray (PAG). We were unable to distinguish a clear boundary between these structures. Labeled neurons were also found in the adjacent retroparafascicular nucleus (RPF) (Fig. 16). These diencephalic nuclei were mainly labeled ipsilaterally. More caudally, the nucleus of Darkschewitsch (Dk) and interstitial nucleus of Cajal ( $\mathrm{InC}$ ) contained a few labeled cells with an ipsilateral dominance (Fig. 5, 6). In regions at the rostral level of the posterior commissure (pc), two or three neurons were seen in the nucleus of posterior commissure (PCom) on both sides with a contralateral predominance (Fig. 16). The magnocellular nucleus of posterior commissure (MCPC) also contained a few labeled neurons on the contralateral side (Fig. 5, 16).

\section{Hypothalamus}

Labeled neurons were present in the rostral anterior parvicellular part (PaAP) and the caudal posterior part $(\mathrm{PaPo})$ of the paraventricular hypothalamic nucleus. A prominent cluster of densely labeled cells was found in the caudal posterior part of the paraventricular hypothalamic nucleus, where they formed a compact hook shaped graph adjacent to the medial part of ZID (Fig. 2, 16). Ventral to PaPo, the ventromedial hypothalamic nucleus (VMH) and the lateral part of the retrochiasmatic nucleus (RChL) contained a few labeled cells. Labeled cells were also found in the peduncular part of the lateral hypothalamus (PLH), magnocellular nucleus of the lateral hypothalamus (MCLH), and the adjacent tuberal region of lateral hypothalamus (TuLH) (Fig. 2, 3, $4,16,17)$. There were a few labeled neurons in the subthalamic nucleus (STh) (Fig. 3). Note that the subthalamic nucleus should be considered to be part of the hypothalamus from a developmental standpoint (Puelles et al. 2007). The posterior hypothalamic nucleus (PH) contained a few lightly labeled cells (Fig. 4). The labeled hypothalamic cells were almost all ipsilateral, except those in PLH, which was bilaterally labeled with an ipsilateral predominance.

\section{Red nucleus}

Many large neurons were strongly labeled in the magnocellular part of the red nucleus (RMC) of the contralateral side, with fewer positive neurons in the parvicellular part of the red nucleus (RPC) on both sides (Fig. 5, 6, 16, 17). Labeled neurons of RMC were evenly distributed from medial to lateral. In sagittal sections, more neurons were found in the caudal part than in the rostral part (Fig. 16, 17).

\section{Mesencephalic reticular formation and tectal nuclei}

A few labeled neurons were seen in the mesencephalic reticular nucleus (mRt) (Fig. 6, 7, 8, 17, 18). These cells were spread over a large area of the midbrain, but were sparsely distributed on the contralateral side. Labeled neurons on the ipsilateral side were more densely packed than the contralateral side at the level of the caudal pole of the medial geniculate (MG) and more caudally. The ipsilateral lateral periaqueductal gray (LPAG) contained a small number of labeled neurons. More caudally, neurons of the dorsomedial periaqueductal gray (DMPAG) were labeled as well. LPAG and ventrolateral periaqueductal gray (VLPAG) were both labeled on 
the ipsilateral side in coronal sections at the level of the oculomotor nucleus $(3 \mathrm{~N})$ (Fig. 6, 7, 8). In sagittal sections, the labeled neurons in PAG formed a column extending from ventral to the inferior colliculus (IC) to prosomere 1, bending rostroventrally at the junction of the superior colliculus (SC) and the pretectum (Fig. 16). These labeled neurons were small and spindle shaped. Ventral to VLPAG, the cells of the supraoculomotor periaqueductal gray (Su3) were labeled bilaterally with an ipsilateral dominance (Fig. 6, 7). More ventrally, cells of the pre-Edinger-Westphal (PrEW), Edinger-Westphal (EW), and the medial accessory oculomotor (MA3) nuclei were lightly labeled bilaterally with an ipsilateral predominance.

In the caudal SC, there were two or three labeled neurons in the deep white (DpWh) and deep gray $(\mathrm{DpG})$ layers in each section on the contralateral side (Fig. 6). Laterally and caudally, there were five to ten neurons labeled in the region through the rostral $1 / 3$ of the precuneiform area $(\mathrm{PrCnF})$ on the ipsilateral side (Fig. 7, 8, 17).

\section{Vestibular nuclei}

Labeled neurons were found in all major nuclei of the vestibular complex. The lateral (LVe) and the superior $(\mathrm{SuVe})$ vestibular nuclei were ipsilaterally labeled (Fig. 10,11). The medial vestibular nucleus (MVe) and the spinal vestibular nucleus (SpVe) were bilaterally labeled (Fig. 10, 11, 12, 13, 16, 17, 18). The labeled neurons were mainly large stellate cells and the labelling was intense, especially in LVe (Fig. 10, 11, 12, 13, 16, 17, 18). In MVe, most of the labeled neurons were concentrated in the magnocellular part (MVeMC); only a small number of neurons were located in the parvicellular part (MVePC).

\section{Trigeminal nucleus}

A few labeled neurons were found in the dorsomedial (Pr5DM) and ventrolateral (Pr5VL) parts of the principal sensory trigeminal nucleus on both sides. These neurons were either spindle shaped or triangular (Fig. 9, 10, 18). The labeled neurons in the oral spinal trigeminal nucleus (Sp5O) and the interpolar spinal trigeminal nucleus (Sp5I) were more numerous and more densely packed than in Pr5DM and Pr5VL. Most of these labeled neurons were large triangular or stellate cells with prominently labeled dendrites. They were concentrated in the ventral portion of these two nuclei (Fig. 11, 12, 13, 14, 18). Labeled neurons in the caudal spinal trigeminal nucleus (Sp5C) were smaller and less clustered than those in Sp5O and Sp5I, and were only found in the dorsal portion of this nucleus (Fig. 15, 17, 18). At the level of rostral part of the motor trigeminal nucleus, a few small labeled neurons were observed in the space between the motor trigeminal nucleus (5N) and Pr5DM, possibly the area identified as parvicellular motor trigeminal nucleus, and in the area dorsal to $5 \mathrm{~N}$ [probably the supratrigeminal nucleus (Su5)] on the ipsilateral side (Fig. 9).

\section{Nucleus of the solitary tract}

Small to medium sized stellate neurons were labeled in the nucleus of solitary tract (Sol) with the majority present in the ventral (SolV) and lateral (SolL) parts of the nucleus on the ipsilateral side. The size of these neurons was smaller than those in the nearby spinal vestibular nucleus. In the caudal part of Sol, some labeled neurons were observed in the medial (SolM) and commissural (SolC) subdivisions (Fig. 13-17).

\section{Cuneate and gracile nuclei}

Labeled neurons were observed in the ipsilateral cuneate $(\mathrm{Cu})$ and gracile $(\mathrm{Gr})$ nuclei, especially in their rostral parts. These labeled neurons were similar in appearance to those in the adjacent medullary reticular nucleus (Fig. 14-17)

\section{Hindbrain reticular formation and related nuclei}

A prominent column of labeled neurons was found lateral to the rostral oral pontine reticular nucleus $(\mathrm{PnO})$ and medial to the lateral lemniscus (11); this region corresponds to the paralemniscal nucleus (PL) of Franklin and Paxinos (2008). These labeled neurons extended from the ventral portion of PL to the level dorsal to the superior cerebellar peduncle (scp). Some of these labeled neurons appear to lie within the triangular nucleus of the lateral lemniscus (TrLL) and the medial paralemniscal nucleus (MPL) (Fig. 7, 8, 18). A small cell group dorsal to the rubrospinal tract (rs) contained a small cluster of labeled neurons; we identify this group as the epirubrospinal nucleus (ERS) of Paxinos and Watson (2007). These labeled neurons were smaller than those in adjacent PnO (Fig. 8).

Labeled neurons were observed in the lateral part of $\mathrm{PnO}$, in an area medial to the pedunculotegmental nucleus (PTg). PTg also contained labeled neurons (Fig. 7). In more caudal sections, labeled neurons in PnO were more medially placed. In the rostral $\mathrm{PnO}$, labeled neurons were principally on the contralateral side; in the middle and caudal parts, labeled cells were principally on the ipsilateral side. Labeled cells in the caudal part of pontine reticular nucleus $(\mathrm{PnC})$ appeared similar in size and shape to those in the caudal PnO. Labeled cells were present in the ventral part of pontine reticular nucleus $(\mathrm{PnV})$ and they were similar to those large cells in the gigantocellular reticular nucleus (Gi) (Fig. 9, 10). Most of the neurons in PnO, PnC, and PnV were large and strongly labeled. 
Labeled neurons were found in the Kölliker-Fuse nucleus (KF), medial parabrachial nucleus (MPB), and lateral parabrachial nucleus (LPB). The neurons in KF were bilaterally labeled and those in MPB and LPB were mainly labeled ipsilaterally. Labeled neurons in these nuclei appeared similar in shape, but smaller than labeled neurons in $\operatorname{Pr} 5$ (Fig. 9, 18).

At the level of the rostral end of the fourth ventricle (4V), a dense cluster of labeled neurons was found in the ipsilateral Barrington's nucleus (Bar). Lateral to Bar, a few labeled neurons were observed in the ipsilateral locus coeruleus (LC) (Fig. 10). Labeled neurons in the subcoeruleus nucleus extended from the alpha part of the subcoeruleus nucleus (SubCA) to the dorsal (SubCD) and the ventral (SubCV) parts of the subcoeruleus nucleus (Fig. 9). The labeling was predominantly ipsilateral. In sagittal sections, labeled neurons in the subcoeruleus nucleus are seen to form a crescent which partly surrounded 5N (Fig. 17). A small number of labeled neurons were observed in the contralateral A5 region (Fig. 10).

A few spindle shaped neurons were observed in the parvicellular reticular nucleus (PCRt) and the intermediate reticular nucleus (IRt) on both sides (Fig. 10-18). In the caudal hindbrain, labeled neurons were concentrated in the caudal part of IRt between the dorsal $(\mathrm{MdD})$ and ventral $(\mathrm{MdV})$ parts of the medullary reticular nuclei, and were mainly in the ipsilateral IRt (Fig. 13, 14, 15, 17). At the same level, a large number of labeled neurons were found in MdD and MdV with an ipsilateral predominance (Fig. 14-17). Medial to MdV, a small number of neurons was labeled in the paramedian reticular nucleus (PMn) (Fig. 14)

At the level of the abducens nucleus $(6 \mathrm{~N})$, a large number of labeled neurons were observed in $\mathrm{Gi}$, the lateral paragigantocellular reticular nucleus (LPGi), the alpha part of the gigantocellular reticular nucleus (GiA), and the ventral part of the gigantocellular reticular nucleus $(\mathrm{GiV})$. There were more labeled neurons on the ipsilateral side than the contralateral side (Fig. 11, 12, 13, 16, 17). In GiA and GiV, labeled neurons formed an arch on the ipsilateral side covering the pyramidal tract (py) and the medial lemniscus (ml). Labeled neurons in the dorsal paragigantocellular reticular nucleus (DPGi) were predominantly contralateral (Fig. 11, 12). Ventral to LPGi, a small number of labeled neurons were observed in the parapyramidal nucleus (PPy) bilaterally (Fig. 11). In some cases, a few labeled neurons also were found in the area ventral to the facial nucleus $(7 \mathrm{~N})$, which is likely to correspond to the retrotrapezoid nucleus (RTz) (Smith et al. 1989) (Fig. 11).

In the raphe, labeled neurons were found in the raphe magnus nucleus (RMg), raphe interpositus nucleus (RIP), raphe obscurus nucleus (ROb), and the raphe pallidus nucleus (RPa) (Fig. 9-13). These labeled neurons were mostly oriented horizontally in coronal sections. They were smaller than the labeled neurons in PnC and Gi. Lateral to the LPGi, a few labeled neurons were found in the rostroventrolateral reticular nucleus (RVL) bilaterally (Fig. 12). Dorsal to this nucleus, a small cluster of labeled neurons was found in the compact part of the nucleus ambiguus (AmbC). Ventral to AmbC, labeled neurons were observed in the Bötzinger complex (Bo), pre-Bötzinger complex (PrBo), and the rostral ventral respiratory group (RVRG) (Fig. 12-14). More caudally, a few labeled neurons were observed in all parts of the contralateral retroambiguus nucleus (RAmb) (Fig. 15).

\section{Cerebellar nuclei}

Intensely labeled neurons were observed in the contralateral anterior interposed cerebellar nucleus (IntA), posterior interposed cerebellar nucleus (IntP), and medial cerebellar nucleus (Med), including the dorsal lateral protuberance (MedDL) (Fig. 11, 12, 16-18). The intensity of labeling was similar to that in LVe.

\section{Estimates of the number of labeled cells}

The estimates of the number of labeled cells in each nucleus or area are shown in Table. 1. The data for two animals are presented. While a sample of two has limitations, it is notable that the counts for large areas do not vary by more than $10 \%$ between the two cases. The total counts (all areas, contralateral and ipsilateral) for the two cases are almost identical. The counts show that the contribution of the motor and somatosensory cortex is only about $25 \%$ of the total, whereas the brainstem tegmental and reticular nuclei account for over $50 \%$ of the total. The contribution from the red nucleus was about $7 \%$ of the total.

\section{Discussion}

This study confirms that the overall pattern of origin of descending spinal tracts in the mouse is similar to that found in other species (Hayes and Rustioni 1981; Leong et al. 1984; Carlton et al. 1985; Gross and Oppenheim 1985; Nudo and Masterton 1988; Carretta et al. 2001). The present study has revealed a number of sites of origin of descending spinal tracts that were previously unrecognized in the mouse. The major significance of this report is that it provides a much-needed baseline for study of recovery of descending tracts after experimental spinal cord injury in the mouse.

\section{Ipsilateral versus contralateral projections}

In our experiments, we attempted to make very large injections in order to identify all cell groups that project to the spinal cord. Because of this, there was a small amount of spread across the midline in a number of cases. 
This means that the distinction between ipsilateral and contralateral labeling in our data was somewhat compromised. While we would have preferred to have strictly unilateral injections, our main aim was to label as many cell groups as possible, and we therefore were prepared to accept a small blurring of the distinction between ipsilateral and contralateral origins.

\section{Cerebral cortex}

We found many labeled cells in the contralateral motor and the somatosensory areas. This is consistent with previous studies on the origin of the corticospinal tract in mammals (Hayes and Rustioni 1981; Miller 1987; Casale et al. 1988; Nudo and Masterton 1990; Masson et al. 1991; Rathelot and Strick 2006). The exception is the hedgehog, in which the majority of labeled neurons are observed in the ipsilateral cortex (Michaloudi et al. 1988). Most of the labeled cells we identified are large pyramidal neurons in layers 5 and 6 . A small number of labeled neurons were found in the ipsilateral motor and somatosensory areas. This might represent the origin of ipsilateral corticospinal tract, but it is also possible that some of these cells were labeled by the small amount of retrograde tracer that spread across the midline of the spinal cord in some cases. We found that many labeled neurons were present in M1, S1FL, S1HL, and S1Tr of the somatosensory cortex. This is consistent with the findings of Li et al (1990) and Tracey (2004) in rats. Neurons in the parietal association cortex (PtA), secondary visual cortex (V2), insular cortex, and prefrontal cortex have been shown to project to the spinal cord in the rat (Miller 1987). However, we did not find labeled cells in these areas.

We estimate that there are about 13,350 labeled cells in the motor cortex (M1 plus M2) and about 9,270 labeled cells in the somatosensory cortex (all S1 areas plus S2) (see Table. 3). When compared with the number of labeled neurons in the red nucleus and hindbrain reticular formation (around 58,190), the motor and somatosensory cortex contribution $(22,620)$ is not a large component of the total descending projection to the spinal cord (see Table. 4). This is consistent with a view that the corticospinal fibers arising in the motor cortex are not a major contributor to motor control in mice (Watson and Harvey 2009). Moreover, it has been shown that about $90 \%$ of corticospinal fibers are distributed in the dorsal horn and intermediate lamina of the spinal cord (mainly laminae 3-5), and none reach lamina 7 or 9 in the mouse (Bareyre et al. 2005). This reinforces the argument that the mouse corticospinal tract is an insignificant player in motor control, compared to the role of this tract in primates such as the rhesus monkey, in which most of the corticospinal fibers terminate in lamina 7 and 9 of the ventral horn (Dum and Strick 1996). Given its extensive termination in the dorsal horn, the mouse corticospinal tract may be more involved in modulating sensory information from the spinal cord rather than the control of limb movement. This means that the role of corticospinal fibers in the recovery of movement after spinal cord injury must be interpreted with caution.

\section{Hypothalamic and diencephalic areas}

Descending projections from the hypothalamus and diencephalon have been identified in a wide range of mammalian and non-mammalian vertebrates. The origin of these neurons varies between non-mammalian classes of vertebrates, but the descending projections most commonly arise from a homologue of the paraventricular nucleus and at least one cell group in the ventral thalamus (Smeets and Timerick 1981; Berk and Finkelstein 1983; Prasada Rao et al. 1987; Masino and Knudsen 1992; Rao et al. 1993; New et al. 1998; Cruce et al. 1999; Sanchez-Camacho et al.2002; Barreiro-Iglesias et al. 2008). In common with a number of studies in mammals (Basbaum and Fields 1979; Sawchenko and Swanson 1982; Leong et al. 1984; Holstege 1987a; Masson et al. 1991; Hallbeck and Blomqvist 1999; Hallbeck 2000; Kc et al. 2002), we found labeled neurons in the ipsilateral paraventricular hypothalamus, the medial part of ZID, and in LH and PH. A small number of weakly labeled neurons were found in DM. We also found labeled neurons in a number of caudal diencephalic nuclei, notably PF and SPF. These latter findings are consistent with those of Schwanzel-Fukuda et al (1984), Nudo and Masterton (1988), Takada (1993), and Marini et al (1999).

Nuclei of the pretectal area (including MCPC, PCom, InC, and Dk) have been shown to project to the spinal cord in a range of different vertebrates (Castiglioni et al. 1978; Crutcher et al. 1978; Leong et al. 1984; Carlton et al. 1985; Gross and Oppenheim 1985; Nudo and Masterton 1988; Masino and Knudson 1992; Cruce et al. 1999; de Boer-van Huizen and ten Donkelaar 1999; Sanchez-Camacho et al. 2001a; Satoda et al.2002). We found many labeled neurons in ipsilateral $\mathrm{InC}, \mathrm{Dk}$, and $\mathrm{EW}$, and a small number of neurons in PCom (bilateral) and the contralateral MCPC. This is consistent with the findings cited above. Developmentally, these pretectal nuclei belong to prosomere 1 of diencephalon (Puelles et al, 2007), therefore they are discussed here.

\section{Red nucleus}

The red nucleus sends a major tract to the contralateral spinal cord in mammalian and non-mammalian vertebrates (Kuypers et al. 1962; Poirier and Bouvier 1966; Warner and Watson 1972; Miller and Strominger 1973; Castiglioni et al. 1978; Crutcher et al. 1978; Wild et al. 1979; Smeets and Timerick 1981; Huisman et al. 1982; Carlton et al. 1985; Okado and Oppenheim 1985; Prasada Rao et al. 1987; Nudo and Masterton 1988; Masino and Knudson 1992; New et al. 1998; Cruce et al. 1999; Carretta et al. 2001; Satoda et al. 2002; 
Tsukamoto et al. 2003; Chiocchetti et al. 2006; VanderHorst and Ulfhake 2006; Stockx et al. 2007; Warren et al. 2008). As with the corticospinal projection (see above), the exception is the hedgehog, in which the ipsilateral projection is larger than the contralateral (Kunzle 1992).

The neurons of RMC in mammals are topographic organized, with neurons projecting to the cervical cord dorsomedially placed, and those projecting to the lumbar cord ventrolaterally placed (Holstege and Tan 1988).

An ipsilateral rubrospinal component has also been identified (Martin and Dom 1970; Warner and Watson 1972; Shieh et al. 1983; Holstege 1987b; Holstege and Tan 1988; Michaloudi et al 1988; Kunzle 1992). Consistent with the majority of mammalian studies cited above, we found many labeled neurons in the contralateral RMC, and a few labeled neurons in RPC. According to our estimates, the red nucleus projection to the spinal cord represents about $7 \%$ of the total (as measured by comparing the number of labeled cells in the red nucleus with the total number of labeled cells).

\section{Tectum}

A projection from the midbrain tectum (SC in mammals) to the contralateral spinal cord is common to a variety of vertebrates that have been studied (Altman and Carpenter 1961; Nyberg-Hansen 1964a; Martin 1969; Kuypers and Maisky 1975; Graham 1977; Harting 1977; Basbaum and Fields 1979; Hayes and Rustioni 1981; Huerta and Harting 1982; Leong et al. 1984; Carlton et al. 1985; Nudo and Masterton 1988; Masson et al. 1991; Olivier et al. 1991; Cruce et al. 1999; Satoda et al. 2002). However, it is notable that ten Donkelaar (1976) did not find tectospinal projections in three reptile species he studied. Previous studies in mammals found that the tectospinal neurons were mainly located in the intermediate gray layer of the superior colliculus (InG), but were also present in DpG(e.g. Nudo and Masterton, 1988). This pattern was confirmed by our tracing studies. In our material, the long axis of the spinally-projecting neurons was parallel to the layers of SC, whereas in the monkey tectospinal neurons are aligned perpendicular to the collicular layers (Castiglioni et al. 1978).

The number of cells giving rise to tectospinal tract fibers in mammals is surprisingly small (Nudo and Masterton 1989); carnivores had the largest number of spinally projecting cells in the contralateral SC (628 in the raccoon and 909 in the cat), but in 7 species of primates studied the number of spinally projecting cells averaged only 220. The average for 23 non-carnivore mammals studied was 243 . On the basis of our counts in the mouse, we estimate that there are about 160 spinally projecting cells in the superior colliculus. Nudo and Masterton (1989) suggested that the influence of the tectum on neck movement may be chiefly mediated by tectal projections to hindbrain nuclei, which in turn project to the cervical spinal cord.

\section{Other midbrain nuclei}

The midbrain PAG has been shown to project to the spinal cord in a number of mammals (Castiglioni et al. 1978; Hayes and Rustioni 1981; Mantyh 1983; Carlton et al. 1985; Nudo and Masterton 1988; Masson et al. 1991; Cowie and Holstege 1992; Kunzle 1992; Satoda et al. 2002; VanderHorst and Ulfhake 2006). In most cases the projection was found to be ipsilateral (Castiglioni et al. 1978; Mantyh 1983; Carlton et al. 1985; Nudo and Masterton 1988; Cowie and Holstege 1992; VanderHorst and Ulfhake 2006 ), but Hayes and Rustioni (1981) identified a contralateral projection arising from LPAG, and others found a bilateral projection (Masson et al. 1991; Kunzle 1992; Satoda et al. 2002). We found labeled neurons in the ipsilateral LPAG, VLPAG, and DMPAG. Some labeled neurons were also observed in the pretectal PAG at the rostral level of the red nucleus. In this area, labeled neurons form a small cluster which is adjacent to Lth. Our result is consistent with most of studies on mammals as mentioned above.

Spinal projecting neurons have been found in the mesencephalic trigeminal nucleus (Me5) (Matsushita et al. 1981; Leong et al. 1984; Michaloudi et al. 1988; Nudo and Masterton 1988; Sanchez-Camacho et al. 2001a), but we did not observe labeled neurons in this nucleus in our experiments. We did observe a number of labeled neurons in bilateral $\mathrm{mRt}$, a finding which has been previously reported by other studies (Leong et al. 1984; Michaloudi et al. 1988; Webster and Steeves 1988; Hassouna et al. 2001).

\section{Vestibular nuclei}

Two main vestibulospinal tracts, the lateral and the medial, have been described. The lateral tract arises from the ipsilateral LVe and is driven by the saccule and utricle (Nyberg-Hansen 1964b; Peterson and Coulter 1977; Basbaum and Fields 1979; Hayes and Rustioni 1981; Leong et al. 1984; Carlton et al. 1985; Michaloudi et al. 1988; Nudo and Masterton 1988; Masson et al. 1991; Masino and Knudson 1992; Wada et al. 1993; Sato et al. 1996; Sato et al. 1997); it extends the full length of the spinal cord (Hayes and Rustioni 1981; Wada et al. 1993). The medial vestibulospinal tract arises from MVe and SpVe bilaterally, and is driven by the semicircular canals (Nyberg-Hansen 1964b; Akaike et al. 1973; Carleton and Carpenter 1984; Cox and Peusner 1990). SuVe has also been found to contain spinal projecting neurons, and these cells are concentrated in the caudal or ventral portion of this nucleus (Leong et al. 1984; Kitao et al. 1993). Consistent with these previous studies, we found medium to large labeled neurons in MVe, SpVe, and LVe, and a few labeled cells in SuVe.

A third vestibulospinal tract, the caudal vestibulospinal tract, has been described by Peterson et al (Peterson et al. 
1978). They showed that it arises from the caudal MVe, SpVe, and vestibular group F. However, a more recent study argues that it originates only from the caudal MVe (Bankoul and Neuhuber 1992). In our study, labeled cells were found in the caudal MVe and the caudal SpVe, but labeled cells were not found in the vestibular group F.

\section{The nucleus of solitary tract}

This nucleus is an important visceral sensory center related to such functions as swallowing, respiration function, and sensation from the internal organs (Jean 1972; Ogawa et al. 1984; Pantaleo and Corda 1986). Consistent with its role in respiratory regulation, it has been shown to project to the phrenic motor nucleus in the cervical spinal cord and to ventral horn at thoracic levels (Crutcher et al. 1978; Kneisley et al. 1978; Loewy and Burton 1978; Smeets and Timerick 1981; Leong et al. 1984; Michaloudi et al. 1988; Mtui et al. 1993; Cruce et al. 1999; Stockx et al. 2007). The solitariospinal tract has been shown to reach lumbar and sacral segments (Carlton et al. 1985; Michaloudi et al. 1988; Masson et al. 1991). In previous studies, most of the spinal projecting neurons were found to be medium sized cells intermingled with a few large neurons in the ventral and ventrolateral subdivisions (Loewy and Burton 1978; Rikard-Bell et al. 1984; Nudo and Masterton 1988; Masson et al. 1991; Mtui et al. 1993; Sanchez-Camacho et al. 2001a). The medium sized cells of the ventrolateral subdivision (SolVL) were shown to project mainly to the cervical spinal cord, while the large SolVL neurons project mainly to the thoracic spinal cord (Loewy and Burton 1978). Smaller spinal projections were found to arise from the intermediate subdivision (SolI) and the commissural subdivision (SolC) (Loewy and Burton 1978; Leong et al. 1984; Mtui et al. 1993). We found labeled cells in the nucleus of the solitary tract on both sides, with an ipsilateral predomince. The majority of labeled neurons were observed in SolV, SolL on the ipsilateral side. Some labeled neurons were observed in the caudal SolM and SolC of this nucleus. These neurons were small to medium sized and lightly labeled compared with labeled neurons in the nearby reticular formation.

\section{The sensory trigeminal nuclei of the hindbrain}

We found labeled cells in Pr5 and all parts of spinal trigeminal nucleus. The distribution was bilateral, but there was an ipsilateral predominance in Pr5 and Sp5C. In sagittal sections, labeled neurons in Pr5, Sp5O, and Sp5I are seen to form a continuous rostrocaudal band in the ventral part of the trigeminal complex. A stripe of labeled cells was observed in the area between $\operatorname{Pr} 5$ and $5 \mathrm{~N}$. This area has been identified as the intertrigeminal area (Int5) (Chamberlin and Saper 1998; Radulovacki et al. 2003; Song et al. 2006), but it may overlap with the parvicellular trigeminal nucleus of Franklin and Paxinos (2008). Cells dorsal to Int5 appear to lie in Su5. Many previous studies have shown that Sp5O, Sp5I, and Sp5C give rise to axons which reach the spinal cord (Kuypers and Maisky 1975; Craig 1978; Burton et al. 1979; Matsushita et al. 1981; Ruggiero et al. 1981; Leong et al. 1984; Gross and Oppenheim 1985; Phelan and Falls 1991; Masino and Knudson 1992; Diagne et al. 2006). Our results are consistent with these studies. As noted above, Me5 has also been identified as the source of descending fibers to the spinal cord (Matsushita et al. 1981), but we did not find labeled cells in this nucleus.

\section{Locus coeruleus and the subcoeruleus area}

Ipsilateral spinal projections from LC have been documented in a variety of vertebrate species (Hancock and Fougerousse 1976; Basbaum and Fields 1979; Guyenet 1980; Hayes and Rustioni 1981; Leong et al. 1984; Carlton et al. 1985; Fritschy et al. 1987; Michaloudi et al. 1988; Clark and Proudfit 1991; Sanchez-Camacho et al. 2001a; Sanchez-Camacho et al. 2001b; VanderHorst and Ulfhake 2006). We found labeled cells in the ventral portion of the ipsilateral LC, but these cells were not as densely packed as those labeled cells in the adjacent Bar (Russo et al. 2004). A few lightly labeled cells were seen in the contralateral LC.

The adjacent subcoeruleus area has also been shown to contain spinal projecting neurons (Kneisley et al. 1978; Hayes and Rustioni 1981; Leong et al. 1984; Carlton et al. 1985; Okado and Oppenheim 1985; Tsukamoto et al. 2003; VanderHorst and Ulfhake 2006). Our results are consistent with these studies. We found labeled neurons in the subcoeruleus nucleus bilaterally with an ipsilateral predominance. These labeled neurons are smaller than those in PnO. In sagittal sections, the band of labeled cells forms a characteristic crescent along the rostral border of $5 \mathrm{~N}$.

\section{Cerebellar nuclei}

The cerebellospinal pathway has been shown to originate from the contralateral Med and interposed cerebellar nuclei (IntA, IntP) (Batton et al. 1977; Bangma et al. 1984; Leong et al. 1984; Gross and Oppenheim 1985; Nudo and Masterton 1988; Arends and Zeigler 1991; Sanchez-Camacho et al. 2001a). We found many labeled neurons in IntA, IntP, and Med on the contralateral side.

\section{Gracile and cuneate nuclei}

We found a small number of labeled cells in $\mathrm{Cu}$ and $\mathrm{Gr}$, which is consistent with previous reports on spinal projections from these nuclei in the rat, hedgehog, cat, and monkey (Burton and Loewy 1977; Carlton et al. 
1985; Michaloudi et al. 1988; Kudo et al. 1993). In our study, most of the labeled neurons were small to medium sized and located in the rostroventral part of these two nuclei.

\section{Reticular nuclei of the hindbrain}

We consider the reticular formation of the hindbrain to be made up of a medial magnocellular column (chiefly $\mathrm{PnO}, \mathrm{PnC}, \mathrm{Gi}, \mathrm{MdV}$ ) and a lateral parvicellular column (PCRt, PCRtA, MdD), separated by an intermediate nucleus (IRt). We do not consider the precerebellar nuclei, LC, or the raphe nuclei to be integral parts of these reticular columns because these former groups are developmentally and functionally distinct. The respiratory neuron groups maybe specialized part of the reticular formation, we will consider them separately.

The magnocellular nuclei of the reticular formation have been shown to give rise to major projections to the spinal cord in a wide variety of vertebrate species (Crutcher et al. 1978; Kneisley et al. 1978; Basbaum and Fields 1979; Zemlan and Pfaff 1979; Goode et al. 1980; Hayes and Rustioni 1981; Martin et al. 1982; Leong et al. 1984; Carlton et al. 1985; Oka et al. 1986; Sirkin and Feng 1987; Michaloudi et al. 1988; Nudo and Masterton 1988; Shen et al. 1990; Holstege 1991; Kausz 1991; Masson et al. 1991; Hobbelen et al. 1992; Kudo et al. 1993; Wada et al. 1993; Aicher et al. 1995; Cruce et al. 1999; de Boer-van Huizen and ten Donkelaar 1999; Carretta et al. 2001; Sanchez-Camacho et al. 2001; Stockx et al. 2007; Reed et al. 2008). While nomenclatural inconsistencies abound, we consider that the magnocellular reticular nuclei should be taken to include $\mathrm{PnO}, \mathrm{PnC}$, PnV, Gi (including GiA, GiV), DPGi, and LPGi.

We found a large number of labeled neurons in bilateral PnO and PnC. Most of labeled neurons were larger than those labeled neurons in the subcoeruleus nucleus. Labeled neurons were found to be closer to the midline in more caudal sections than they were in rostral sections. We also observed a very large number of labeled neurons in $\mathrm{Gi}$ (GiA, GiV, Gi). Labeled neurons in GiA and GiV are predominantly ipsilaterally located and form an arch with neurons in raphe nuclei and LPGi. Labeled neurons in the dorsal part of Gi are more sparsely distributed with a contralateral dominance. Some labeled neurons in Gi are larger than those in GiA and GiV. A few labeled neurons were observed in DPGi. These findings are consistent with other studies of the gigantocellular nuclei (Kneisley et al. 1978; Zemlan and Pfaff 1979; Hayes and Rustioni 1981; Newman et al. 1983; Leong et al. 1984; Carlton et al. 1985; Metcalfe et al. 1986; Oka et al. 1986; Prasada Rao et al. 1987; Glover and Petursdottir 1988; Webster and Steeves 1988; Shen et al. 1990; Kausz 1991; Masson et al. 1991; Webster and Steeves 1991; Rao et al. 1993; Wada et al. 1993; Aicher et al. 1995; New et al. 1998; Cruce et al. 1999; Carretta et al. 2001; Gahtan and O’Malley 2003; Tsukamoto et al. 2003), and almost identical to the findings of VanderHorst and Ulfhake (2006) in the mouse.

It has been reported that PCRt and IRt have spinal projecting neurons (Gross and Oppenheim 1985; Nudo and Masterton 1988; Stockx et al. 2007). We found a few neurons in these two nuclei bilaterally. In the caudal portion of IRt, the density of labeled neurons increases, and in the most caudal hindbrain sections, they form a band that separates MdV and MdD. At the same level, a large number of labeled neurons were seen in both $\mathrm{MdD}$ and $\mathrm{MdV}$ with an ipsilateral predominance. Labeled neurons in each of these two nuclei form a band which is parallel to the band of labeled neurons in IRt. In the dorsal portion of MdD, IRt, and MdV, labeled cells are more numerous in the more caudal regions. These findings are consistent with similar studies in other mammals (Peterson et al. 1975; Hayes and Rustioni 1981; Leong et al. 1984; Carlton et al. 1985; Leite-Almeida et al. 2006).

\section{Nucleus ambiguus and the hindbrain respiratory nuclei}

We found labeled cells in nucleus ambiguus and related respiratory nuclei. In the AmbC, the labeled cells form a small cluster bilaterally with a contralateral predominance. This is consistent with other reports (Leong et al. 1984; Gross and Oppenheim 1985; Nudo and Masterton 1988; Lan et al. 1997; Ellenberger 1999). Ventral to Amb, labeled neurons were found in RVL, Bo, PrBo, and RVRG. Labeled cells in these latter nuclei are not as densely packed as AmbC: a finding which is consistent with results of previous studies (Kausz 1991; Mtui et al. 1995; Lan et al. 1997; Ellenberger 1999; Buhler et al. 2004; Russo et al. 2005). Cells of the contralateral RAmb are labeled but the density of labeled cells is much less than that of Amb. This is consistent with reports of studies in cat, rat, and mouse (Hardy et al. 1998; Gerrits et al. 2000; VanderHorst 2005; Boers et al. 2006).

\section{Raphe nuclei}

The raphe nuclei have been reported to project to the spinal cord in a variety of species (Kneisley et al. 1978; Leichnetz et al. 1978; Basbaum and Fields, 1979; Zemlan and Pfaff 1979; Hayes and Rustioni 1981; Smeets and Timerick 1981; ten Donkelaar et al. 1981; ten Donkelaar and de Boer-van Huizen 1982; Leong et al. 1984; van Mier and ten Donkelaar 1984; Gross and Oppenheim 1985; Okado and Oppenheim 1985; Edwards et al. 1987; Holstege and Tan 1987; Prasada Rao et al. 1987; Michaloudi et al.1988; Nudo and Masterton 1988; Webster and Steeves 1988; Shen et al. 1990; Kausz 1991; Masson et al. 1991; Hobbelen et al. 1992; Kudo et al. 1993; Rao et al. 1993; Gilbey et al. 1995; New et al. 1998; Adli et al, 1999; Carretta et al. 2001; Sanchez-Camacho et al. 2001a; VanderHorst and Ulfhake 2006). We found labeled neurons in RMg, RPa, ROb, and RIP. The long axis 
of most labeled neurons is oriented horizontally and they are as strongly labeled as those neurons in adjacent Gi and PnC. This is consistent with results from previous studies as mentioned above.

\section{Novel sites of origin of descending spinal fibers}

We found labeled cells in two hindbrain nuclei that have not previously been shown to project to the spinal cord. They are PrCnF and ERS. The rostral part of PrCnF lies between SC dorsally and mRt ventrally, the caudal part of PrCnF lies between IC dorsally and the microcellular tegmental nucleus (MiTg) ventrally (Franklin and Paxinos, 2008). The nucleus has a distinct outline in acetylcholinesterase sections showing in plate 70 of Franklin and Paxinos (2008). This nucleus has not previously been reported to project to the spinal cord. One study found that a large number of neurons projected to the spinal cord from the medial part of the cuneiform nucleus $(\mathrm{CnF})$ in the monkey, but these authors did not mention PrCnF (Castiglioni et al. 1978). In the cat, labeled neurons reported to be in the medial part of $\mathrm{CnF}$ after cervical spinal cord injections (Satoda et al. 2002). It is possible that some of these labeled cells in our sections belong not to $\mathrm{CnF}$ but to PrCnF. We found that labeled neurons in PrCnF were most numerous in the medial portion, close to the labeled neurons of the LPAG, which also contains spinal projecting neurons.

The ERS was identified and named by Paxinos and Butcher (1985), on the basis of positive acetylcholinesterase staining. In the rat and mouse, this nucleus is a group of cells in the upper hindbrain tegmentum, medial to the lateral lemniscus and dorsal to the rubrospinal tract (Paxinos and Franklin 2001). Swanson regards this nucleus as a part of the nucleus of the lateral lemniscus (Swanson 1998), but the patch of acetylcholinesterase staining distinguishes ERS from the nucleus of the lateral lemniscus and the rubrospinal tract (Paxinos and Watson 2007). In the present study, labeled neurons in this nucleus were closely allocated to the dorsal surface of the rubrospinal tract. The small number of labeled cells in ERS lies between the large population of labeled cells in PL and PTg. The labeled cells in ERS are smaller than those in the adjacent PL and PTg.

\section{Sites of origin of descending spinal fibers not previously reported in the mouse}

A projection from PL to the spinal cord has been reported in the rat (Leichnetz et al. 1978) and some other animals (Nudo and Masterton 1988). An anterograde study suggested that the MPL might project to the spinal cord in the mouse, but the data were not conclusive (Dobolyi et al. 2003). We believe that the present study is the first to convincingly demonstrate the presence of a large projection from PL to the spinal cord in the mouse. We found that intensely labeled neurons are distributed along the whole rostrocaudal extent of the contralateral PL. It has been shown that stimulation of PL can inhibit the activity of the dorsal horn (Mokha and Iggo 1987), and these authors suggest that it may play a role in nociception.

In some species (but not in the mouse), the amygdala complex has been shown to send projections to the spinal cord (Mizuno et al. 1985; Sandrew et al. 1986; Nudo and Masterton 1988; Sanchez-Camacho et al. 2001a; Sanchez-Camacho et al. 2002). In amphibians, labeled neurons are located in the ventrocaudal telecephalon, lateral to the preoptic area (Sanchez-Camacho et al. 2001a; Sanchez-Camacho et al. 2002). In mammals, labeled neurons are located in the central and medial nuclei of the amygdala (Mizuno et al. 1985; Sandrew et al. 1986; Nudo and Masterton 1988). We found labeled neurons in the central amygdaloid nucleus (mainly in CeM) in the mouse and also in EAC and BLA. Since fibers from the amygdala do not extend below middle cervical levels (Mizuno et al. 1985), this pathway may play a role in behaviors involving head orientation.

\section{Conclusions}

This study is the first comprehensive report of the sites of origin of descending pathways to the spinal cord in the mouse. It is clear that the distribution of these cell groups is very similar to the findings that have been reported in other mammals. However, following spinal tracer injections, we have identified labeled cells in two hindbrain cell groups that have not previously been reported to project to the spinal cord in any mammal, and in two neuron groups which have not been reported to have spinal projections in the mouse. The findings of this study should be useful to those who are studying recovery after experimental spinal cord injury in mice. This study shows that the corticospinal tract comprises only a small fraction of total projections from the brain to the spinal cord in the mouse. We recommend caution in using corticospinal regrowth as an index of motor recovery after spinal cord injury.

\section{Acknowledgements}

We thank Professor Gulgun Kayalioglu, Dr Yuhong Fu, Dr Yue Qi, and Dr Erika Gyengesi for their helpful suggestions, and we thank Mr Peter Zhao for technical support. This work was supported by the Christopher and Dana Reeve Foundation and an Australia Fellowship awarded to Professor George Paxinos by the National 
Health and Medical Research Council (NHMRC) (466028).

\section{References}

Adli DSH, Stuesse SL, Cruce WLR (1999). Immunohistochemistry and spinal projections of the reticular formation in the northern leopard frog, Rana pipiens. J Comp Neurol 404: 387-407.

Aicher SA, Reis DJ, Nicolae R, Milner TA (1995). Monosynaptic projections from the medullary

gigantocellular reticular formation to sympathetic preganglionic neurons in the thoracic spinal cord. J Comp Neurol 363: 563-580.

Akaike T, Fanardji Vv, Ito M, Kumada M, Nakajima H (1973). Electrophysiological analysis of vestibulospinal reflex pathway of rabbit .1. Classification of tract cells. Exp Brain Res 17: 477-496.

Altman J, Carpenter MB (1961). Fiber projections of superior colliculus in cat. J Comp Neurol 116: 157-177.

Arends JJ, Zeigler HP (1991). Organization of the cerebellum in the pigeon (Columba livia): II. Projections of the cerebellar nuclei. J Comp Neurol 306: 245-272.

Bangma GC, ten Donkelaar HJ, Dederen PJ, de Boer-van Huizen R (1984). Cerebellar efferents in the lizard Varanus exanthematicus. II. Projections of the cerebellar nuclei. J Comp Neurol 230: 218-230.

Bankoul S, Neuhuber WL (1992). A direct projection from the medial vestibular nucleus to the cervical spinal dorsal horn of the rat, as demonstrated by anterograde and retrograde tracing. Anat Embryol, 185: 77-85.

Bareyre FM, Kerschensteiner M, Misgeld T, Sanes JR (2005). Transgenic labeling of the corticospinal tract for monitoring axonal responses to spinal cord injury. Nat Med 11: 1355-1360.

Barreiro-Iglesias A, Villar-Cervino V, Anadon R, Rodicio MC (2008). Descending brain-spinal cord projections in a primitive vertebrate, the lamprey: cerebrospinal fluid-contacting and dopaminergic neurons. J Comp Neurol 511: 711-723.

Basbaum AI, Fields HL (1979). The origin of descending pathways in the dorsolateral funiculus of the spinal cord of the cat and rat: further studies on the anatomy of pain modulation. J Comp Neurol 187: 513-531.

Batton RR, Jayaraman III A, Ruggiero D, Carpenter MB (1977). Fastigial efferent projections in the monkey: an autoradiographic study. J Comp Neurol 174: 281-305.

Berk ML, Finkelstein JA (1983). Long descending projections of the hypothalamus in the pigeon, Columba livia. J Comp Neurol 220: 127-136.

Boers J, Kirkwood PA,de Weerd H, Holstege G (2006). Ultrastructural evidence for direct excitatory retroambiguus projections to cutaneous trunci and abdominal external oblique muscle motoneurons in the cat. Brain Res Bull 68: 249-256.

Buhler AV, Proudfit HK, Gebhart GF (2004). Separate populations of neurons in the rostral ventromedial medulla project to the spinal cord and to the dorsolateral pons in the rat. Brain Res 1016: 12-19.

Burton H, Loewy AD (1977). Projections to the spinal cord from medullary somatosensory relay nuclei. J Comp Neurol 173: 773-792.

Burton H, Craig AD, Poulos DA, Molt JT (1979). Efferent projections from temperature sensitive recording loci within the marginal zone of the nucleus caudalis of the spinal trigeminal complex in the cat. J Comp Neurol 183: 753-777.

Carleton SC, Carpenter MB (1984). Distribution of primary vestibular fibers in the brainstem and cerebellum of the monkey. Brain Res 294: 281-298.

Carlton SM, Chung JM, Leonard RB, Willis WD (1985). Funicular trajectories of brainstem neurons projecting to the lumbar spinal cord in the monkey (Macaca fascicularis): a retrograde labeling study. J Comp Neurol 241: 382-404.

Carretta D, Santarelli M, Vanni D, Carrai R, Sbriccoli A, Pinto F, Minciacchi D (2001). The organisation of spinal projecting brainstem neurons in an animal model of muscular dystrophy. A retrograde tracing study on mdx mutant mice. Brain Res 895: 213-222.

Casale EJ, Light AR, Rustioni A (1988). Direct projection of the corticospinal tract to the superficial laminae of the spinal cord in the rat. J Comp Neurol 278: 275-286.

Castiglioni AJ, Gallaway MC, Coulter JD (1978). Spinal projections from midbrain in monkey. J Comp Neurol 178: 329-345.

Chamberlin NL, Saper CB (1998). A brainstem network mediating apneic reflexes in the rat. J Neurosci 18: 6048-6056.

Chiocchetti R, Bombardi C, Grandis A, Mazzuoli G, Gentile A, Pisoni L, Joechler M, Lucchi ML (2006). Cytoarchitecture, morphology, and lumbosacral spinal cord projections of the red nucleus in cattle. Am J Vet Res 67: 1662-1669.

Clark FM, Proudfit HK (1991). The projection of noradrenergic neurons in the A7 catecholamine cell group to the spinal cord in the rat demonstrated by anterograde tracing combined with immunocytochemistry. Brain Res 547: 279-288. 
Cowie RJ, Holstege G (1992). Dorsal mesencephalic projections to pons, medulla, and spinal cord in the cat: limbic and non-limbic components. J Comp Neurol 319: 536-559.

Cox RG, Peusner KD (1990). Horseradish peroxidase labeling of the central pathways in the medulla of the ampullary nerves in the chicken, Gallus gallus. J Comp Neurol 297: 564-581.

Craig AD (1978). Spinal and medullary input to the lateral cervical nucleus. J Comp Neurol 181: 729-743.

Cruce WLR, Stuesse SL, Northcutt RG (1999). Brainstem neurons with descending projections to the spinal cord of two elasmobranch fishes: Thornback guitarfish, Platyrhinoidis triseriata, and horn shark, Heterodontus francisci. J Comp Neurol 403: 534-560.

Crutcher KA, Humbertson AO, Martin GF (1978). The origin of brainstem-spinal pathways in the North American opossum (Didelphis virginiana). Studies using the horseradish peroxidase method. J Comp Neurol 179: 169-193.

de Boer-van Huizen RT, ten Donkelaar HJ (1999). Early development of descending supraspinal pathways: a tracing study in fixed and isolated rat embryos. Anat Embryol 199: 539-547.

Diagne M, Valla J, Delfini C, Buisseret-Delmas C, Buisseret P (2006). Trigeminovestibular and trigeminospinal pathways in rats: retrograde tracing compared with glutamic acid decarboxylase and glutamate immunohistochemistry. J Comp Neurol 496: 759-772.

Dobolyi A, Palkovits M, Bodnar I, Usdin TB (2003). Neurons containing tuberoinfundibular peptide of 39 residues project to limbic, endocrine, auditory and spinal areas in rat. Neurosci 122: 1093-1105.

Dum RP, Strick PL (1996). Spinal cord terminations of the medial wall motor areas in macaque monkeys. J Neurosci 16: 6513-6525.

Edwards DL, Poletti CE, Foote WE (1987). Evidence for leucine-enkephalin immunoreactive neurons in the medulla which project to spinal cord in squirrel monkey. Brain Res 437: 197-203.

Ellenberger HH (1999). Nucleus ambiguus and bulbospinal ventral respiratory group neurons in the neonatal rat. Brain Res Bull 50: 1-13.

Franklin KBJ, Paxinos G (2008). The mouse brain in stereotaxic coordinates, $3^{\text {rd }}$ edition. Elsevier Academic Press, San Diego.

Fritschy JM, Lyons WE, Mullen CA, Kosofsky BE, Molliver ME, Grzanna R (1987). Distribution of locus coeruleus axons in the rat spinal cord: a combined anterograde transport and immunohistochemical study. Brain Res 437: 176-180.

Gahtan E, O'Malley DM (2003). Visually guided injection of identified reticulospinal neurons in zebrafish: A survey of spinal arborization patterns. J Comp Neurol 459: 186-200.

Galea MP, Darian-Smith I (1994). Multiple corticospinal neuron populations in the macaque monkey are specified by their unique cortical origins, spinal terminations, and connections. Cereb Cortex 4: 166-194. Gerrits PO, Vodde C, Holstege G (2000). Retroambiguus projections to the cutaneus trunci motoneurons may form a pathway in the central control of mating. J Neurophysiol 83: 3076-3083.

Gilbey MP, Futuro-Neto HA and Zhou SY (1995). Respiratory-related discharge patterns of caudal raphe neurones projecting to the upper thoracic spinal cord in the rat. J Auton Nerv Syst 50: 263-273.

Glover JC, Petursdottir G (1988). Pathway specificity of reticulospinal and vestibulospinal projections in the 11day chicken embryo. J Comp Neurol 270: 25-38, 60-21.

Goode GE, Humbertson AO, Martin GF (1980). Projections from the brain stem reticular formation to laminae I and II of the spinal cord. Studies using light and electron microscopic techniques in the North American opossum. Brain Res 189: 327-342.

Graham J (1977). Autoradiographic study of efferent connections of superior colliculus in cat. J Comp Neurol 173: 629-654.

Gross GH, Oppenheim RW (1985). Novel sources of descending input to the spinal cord of the hatching chick. J Comp Neurol 232: 162-179.

Guyenet PG (1980). The coeruleospinal noradrenergic neurons: anatomical and electrophysiological studies in the rat. Brain Res 189: 121-133.

Hallbeck M (2000). Dynorphin mRNA-expressing neurons in the rat paraventricular hypothalamic nucleus project to the spinal cord. Neurosci Lett 285: 161-164.

Hallbeck M, Blomqvist A (1999). Spinal cord-projecting vasopressinergic neurons in the rat paraventricular hypothalamus. J Comp Neurol 411: 201-211.

Hancock MB, Fougerousse CL (1976). Spinal projections from the nucleus locus coeruleus and nucleus subcoeruleus in the cat and monkey as demonstrated by the retrograde transport of horseradish peroxidase. Brain Res Bull 1: 229-234.

Hardy SG, Horecky JG, Presley KG (1998). Projections of the caudal ventrolateral medulla to the thoracic spinal cord in the rat. Anat Rec 250: 95-102.

Harting JK (1977). Descending pathways from the superior collicullus: an autoradiographic analysis in the rhesus monkey (Macaca mulatta). J Comp Neurol 173: 583-612. 
Hassouna E, Yamamoto M, Imagawa T, Uehara M (2001). Distribution of reticulospinal neurons in the chicken by retrograde transport of WGA-HRP. Tissue Cell 33: 141-147.

Hayes NL, Rustioni A (1981). Descending projections from brainstem and sensorimotor cortex to spinal enlargements in the cat. Single and double retrograde tracer studies. Exp Brain Res 41: 89-107.

Hobbelen JF, Gramsbergen A, van Hof MW(1992). Descending pathways and the hopping response in the rabbit. Behav Brain Res 51: 217-221.

Holstege G (1987a). Some anatomical observations on the projections from the hypothalamus to brainstem and spinal cord: an HRP and autoradiographic tracing study in the cat. J Comp Neurol 260: 98-126.

Holstege G. (1987b). Anatomical evidence for an ipsilateral rubrospinal pathway and for direct rubrospinal projections to motoneurons in the cat. Neurosci Lett 74: 269-274.

Holstege G and Tan J (1987). Supraspinal control of motoneurons innervating the striated muscles of the pelvic floor including urethral and anal sphincters in the cat. Brain 110: 1323-1344.

Holstege G, Tan J (1988). Projections from the red nucleus and surrounding areas to the brainstem and spinal cord in the cat. An HRP and autoradiographical tracing study. Behav Brain Res 28: 33-57.

Holstege JC (1991). Ultrastructural evidence for GABAergic brain stem projections to spinal motoneurons in the rat. J Neurosci 11: 159-167.

Huerta MF, Harting JK (1982). Projections of the superior colliculus to the supraspinal nucleus and the cervical spinal cord gray of the cat. Brain Res 242: 326-331.

Huisman AM, Kuypers HGJM, Verburgh CA (1982). Differences in collateralization of the descending spinal pathways from red nucleus and other brain-stem cell groups in cat and monkey. Prog Brain Res 57: $185-217$.

Jean A (1972). Localization and activity of medullary swallowing neurones. J Physiol, 64: 227-268.

Kausz M (1991). Arrangement of neurons in the medullary reticular formation and raphe nuclei projecting to thoracic, lumbar and sacral segments of the spinal cord in the cat. Anat Embryol, 183: 151-163.

Kc P, Haxhiu MA, Tolentino-Silva FP, Wu M, Trouth CO, Mack SO (2002). Paraventricular vasopressincontaining neurons project to brain stem and spinal cord respiratory-related sites. Respir Physiol Neurobiol 133: 75-88.

Kimmel CB, Powell SL, Metcalfe WK (1982). Brain neurons which project to the spinal cord in young larvae of the zebrafish. J Comp Neurol 205: 112-127.

Kitao Y, Okoyama S, Moriizumi T Kudo M (1993). Neurogenetical segregation of the vestibulospinal neurons in the rat. Brain Res 620: 149-154.

Kneisley LW, Biber MP, Lavail JH (1978). Study of origin of brain-stem projections to monkey spinal-cord using retrograde transport method. Exp Neurol 60: 116-139.

Kuchler M, Fouad K, Weinmann O, Schwab ME, Raineteau O (2002). Red nucleus projections to distinct motor neuron pools in the rat spinal cord. J Comp Neurol 448: 349-359.

Kudo N, Furukawa F, Okado N (1993). Development of descending fibers to the rat embryonic spinal-cord. Neurosci Res 16: 131-141.

Kunzle H (1992). Meso-diencephalic regions projecting to spinal cord and dorsal column nuclear complex in the hedgehog-tenrec, Echinops telfairi. Anat Embryol 185: 57-68.

Kuypers HG, Fleming WR, Farinholt JW (1962). Subcorticospinal projections in the rhesus monkey. J Comp Neurol 118: 107-137.

Kuypers HG, Maisky VA (1975). Retrograde axonal transport of horseradish peroxidase from spinal cord to brain stem cell groups in the cat. Neurosci Lett 1: 9-14.

Lakke EA (1997). The projections to the spinal cord of the rat during development: a timetable of descent. Adv Anat Embryol Cell Biol 135: I-XIV, 1-143.

Lan CT, Wu WC, Ling EA, Chai CY (1997). Evidence of a direct projection from the cardiovascular-reactive dorsal medulla to the intermediolateral cell column of the spinal cord in cats as revealed by light and electron microscopy. Neurosci 77: 521-533.

Leichnetz GR, Watkins L, Griffin G, Murfin R, Mayer DJ (1978). Projection from nucleus raphe magnus and other brain-stem nuclei to spinal-cord in rat - Study using HRP blue-reaction. Neurosci Lett 8: 119-124.

Leite-Almeida H, Valle-Fernandes A, Almeida A (2006). Brain projections from the medullary dorsal reticular nucleus: an anterograde and retrograde tracing study in the rat. Neurosci 140: 577-595.

Leong SK, Shieh JY, Wong WC (1984). Localizing spinal-cord-projecting neurons in adult albino rats. J Comp Neurol 228: 1-17.

Li XG, Florence SL, Kaas JH (1990). Areal distributions of cortical neurons projecting to different levels of the caudal brain stem and spinal cord in rats. Somatosens Mot Res 7: 315-335.

Loewy AD, Burton H (1978). Nuclei of the solitary tract: efferent projections to the lower brain stem and spinal cord of the cat. J Comp Neurol 181: 421-449.

Mantyh PW (1983). Connections of midbrain periaqueductal gray in the monkey. II. Descending efferent projections. J Neurophysiol 49: 582-594. 
Marini G, Pianca L, Tredici G (1999). Descending projections arising from the parafascicular nucleus in rats: trajectory of fibers, projection pattern and mapping of terminations. Somatosens Mot Res 16: 207-222.

Martin GF (1969). Efferent tectal pathways of opossum - (Didelphis Virginiana). J Comp Neurol 135: 209-224. Martin GF, Dom R (1970). The rubro-spinal tract of the opposum (Didelphis virginiana). J Comp Neurol 138 : 19-30.

Martin GF, Cabana T, DiTirro FJ, Ho RH, Humbertson AO (1982). Reticular and raphe projections to the spinal cord of the North American opossum. Evidence for connectional heterogeneity. Prog Brain Res 57: 109-129. Masino T, Knudsen EI (1992). Anatomical pathways from the optic tectum to the spinal cord subserving orienting movements in the barn owl. Exp Brain Res 92: 194-208

Masson RL, Sparkes M L, Ritz LA (1991). Descending projections to the rat sacrocaudal spinal cord. J Comp Neurol 307: 120-130.

Matsushita M, Okado N, Ikeda M, Hosoya Y (1981). Descending projections from the spinal and mesencephalic nuclei of the trigeminal nerve to the spinal-cord in the cat - a study with the horseradish-peroxidase technique. $\mathrm{J}$ Comp Neurol 196: 173-187.

Mesulam MM (1978). Tetramethyl benzidine for horseradish peroxidase neurohistochemistry: a noncarcinogenic blue reaction product with superior sensitivity for visualizing neural afferents and efferents. $\mathrm{J}$ Histochem Cytochem 26: 106-117.

Metcalfe WK, Mendelson B, Kimmel CB (1986). Segmental homologies among reticulospinal neurons in the hindbrain of the zebrafish larva. J Comp Neurol 251: 147-159.

Michaloudi H, Dinopoulos A, Karamanlidis AN, Papadopoulos NC, Antonopoulos J (1988). Cortical and brainstem projections to the spinal-cord of the hedgehog (Erinaceus-Europaeus) - a horseradish-peroxidase study. Anat Embryol 178: 259-270.

Miller MW (1987). The origin of corticospinal projection neurons in rat. Exp Brain Res 67: 339-351. Miller RA, Strominger NL (1973). Efferent connections of the red nucleus in the brainstem and spinal cord of the rhesus monkey. J Comp Neurol 152: 327-345.

Mizuno N, Takahashi O, Satoda T, Matsushima R (1985). Amygdalospinal projections in the macaque monkey. Neurosci Lett 53: 327-330.

Mokha SS, Iggo A (1987). Mechanisms mediating the brain stem control of somatosensory transmission in the dorsal horn of the cat's spinal cord: an intracellular analysis. Exp Brain Res 69: 93-106.

Mtui EP, Anwar M, Gomez R, Reis DJ, Ruggiero DA (1993). Projections from the nucleus tractus solitarii to the spinal cord. J Comp Neurol 337: 231-252.

Mtui EP, Anwar M, Reis DJ, Ruggiero DA (1995). Medullary visceral reflex circuits: local afferents to nucleus tractus solitarii synthesize catecholamines and project to thoracic spinal cord. J Comp Neurol 351: 5-26.

New JG, Snyder BD, Woodson KL (1998). Descending neural projections to the spinal cord in the channel catfish, Ictalurus punctatus. Anat Rec 252: 235-253.

Newman DB, Cruce WL, Bruce LL (1983). The sources of supraspinal afferents to the spinal cord in a variety of limbed reptiles. I. Reticulospinal systems. J Comp Neurol 215: 17-32.

Nordlander RH, Baden ST, Ryba TMJ (1985). Development of early brain-stem projections to the tail spinalcord of xenopus. J Comp Neurol 231: 519-529.

Nudo RJ, Masterton RB (1988). Descending pathways to the spinal-cord - a comparative study of 22 mammals. J Comp Neurol 277: 53-79.

Nudo RJ, Masterton RB (1989). Descending pathways to the spinal cord: II. Quantitative study of the tectospinal tract in 23 mammals. J Comp Neurol 286: 96-119.

Nudo RJ, Masterton RB (1990). Descending pathways to the spinal cord, III: sites of origin of the corticospinal tract. J Comp Neurol 296: 559-583.

Nyberg-Hansen R (1964a). The location and termination of tectospinal fibers in the cat. Exp Neurol 9: 212-227. Nyberg-Hansen R (1964b). Origin and termination of fibers from the vestibular nuclei descending in the medial longitudinal fasciculus. An experimental study with silver impregnation methods in the cat. J Comp Neurol 122: 355-367.

Nyberg-Hansen R, Brodal A (1964). Sites and mode of termination of rubrospinal fibres in the cat. An experimental study with silver impregnation methods. J Anat 98: 235-253.

Nyberg-Hansen R (1965). Sites and mode of termination of reticulo-spinal fibers in the cat. An experimental study with silver impregnation methods. J Comp Neurol 124: 71-99.

Ogawa H, Imoto T, Hayama T (1984). Responsiveness of solitario-parabrachial relay neurons to taste and mechanical stimulation applied to the oral cavity in rats. Exp Brain Res 54: 349-358.

Oka Y, Satou M, Ueda K (1986). Descending pathways to the spinal-cord in the hime salmon (landlocked red salmon, Oncorhynchus-Nerka). J Comp Neurol 254: 91-103.

Okado N, Oppenheim RW (1985). The onset and development of descending pathways to the spinal-cord in the chick-embryo. J Comp Neurol 232: 143-161. 
Olivier E, Chat M, Grantyn A (1991). Rostrocaudal and lateromedial density distributions of superior colliculus neurons projecting in the predorsal bundle and to the spinal cord: a retrograde HRP study in the cat. Exp Brain Res 87: 268-282.

Pantaleo T, Corda M (1986). Respiration-related neurons in the medial nuclear complex of the solitary tract of the cat. Respir Physiol 64: 135-148.

Paxinos G, Butcher LL (1985). Organizational principles of the brain as revealed by choline acetyltransferase and acetylcholinesterase distribution and projections. In: Paxinos G (ed) The rat nervous system, First Edition. Elsevier Academic Press, San Diego: 487-521.

Paxinos G, Franklin KBJ (2001). The mouse brain in stereotaxic coordinates, Second Edition. Elsevier Academic Press, San Diego.

Paxinos G, Watson C (2007). The rat brain in stereotaxic coordinates. Elsevier Academic Press, San Diego. Peterson BW, Coulter JD (1977). A new long spinal projection from the vestibular nuclei in the cat. Brain Res 122: 351-356.

Peterson BW, Maunz RA, Fukushima K (1978). Properties of a new vestibulospinal projection, the caudal vestibulospinal tract. Exp Brain Res 32: 287-292.

Peterson BW, Maunz RA, Pitts NG, Mackel RG (1975). Patterns of projection and braching of reticulospinal neurons. Exp Brain Res 23: 333-351.

Phelan KD, Falls WM (1991). A comparison of the distribution and morphology of thalamic, cerebellar and spinal projection neurons in rat trigeminal nucleus interpolaris. Neurosci 40: 497-511.

Poirier LJ, Bouvier G (1966). Red nucleus and its efferent nervous pathways in monkey. J Comp Neurol 128 : 223-243.

Pompeiano O, Brodal A (1957). Experimental demonstration of a somatotopical origin of rubrospinal fibers in the cat. J Comp Neurol 108: 225-251.

Prasada Rao PD, Jadhao AG, Sharma SC (1987). Descending projection neurons to the spinal cord of the goldfish, Carassius auratus. J Comp Neurol 265: 96-108.

Puelles L, Martinez-de-la-Torre M, Paxinos G, Watson C, Martínez S (2007). The chick brain in stereotaxic coordinates. Elsevier Academic Press, New York, Page: 41.

Radulovacki M, Pavlovic S, Saponjic J, Carley DW (2003). Intertrigeminal region attenuates reflex apnea and stabilizes respiratory pattern in rats. Brain Res 975: 66-72.

Rao PD, Jadhao AG, Sharma SC (1993). Topographic organization of descending projection neurons to the spinal cord of the goldfish, Carassius auratus. Brain Res 620: 211-220.

Rathelot JA, Strick PL (2006). Muscle representation in the macaque motor cortex: an anatomical perspective. Proc Natl Acad Sci 103: 8257-8262.

Reed WR, Shum-Siu A, Magnuson DS (2008). Reticulospinal pathways in the ventrolateral funiculus with terminations in the cervical and lumbar enlargements of the adult rat spinal cord. Neurosci 151: 505-517.

Rikard-Bell GC, Bystrzycka EK, Nail BS (1984). Brainstem projections to the phrenic nucleus: a HRP study in the cat. Brain Res Bull 12: 469-477.

Ruggiero DA, Ross CA, Reis DJ (1981). Projections from the spinal trigeminal nucleus to the entire length of the spinal cord in the rat. Brain Res 225: 225-233.

Russo A, Monaco S, Romeo R, Pellitteri R, Stanzani S (2004). Serotonergic collateralized projections from Barrington's nucleus to the medial preoptic area and lumbo-sacral spinal cord. Brain Res 1019: 64-67.

Russo A, Pellitteri R, Romeo R, Stanzani S, Jean A (2005). Branching projections of ventrolateral reticular neurons to the medial preoptic area and lumbo-sacral spinal cord. Behav Brain Funct 1: 17.

Sanchez-Camacho C, Marin O, ten Donkelaar HJ, Gonzalez A (2001a). Descending supraspinal pathways in amphibians. I. A dextran amine tracing study of their cells of origin. J Comp Neurol 434: 186-208.

Sanchez-Camacho C, Marin O, Smeets WJ, ten Donkelaar HJ, Gonzalez A (2001b). Descending supraspinal pathways in amphibians. II. Distribution and origin of the catecholaminergic innervation of the spinal cord. J Comp Neurol 434: 209-232.

Sanchez-Camacho C, Martin O, ten Donkelaar HJ, Gonzalez A (2002). Descending supraspinal pathways in amphibians: III. Development of descending projections to the spinal cord in Xenopus laevis with emphasis on the catecholaminergic inputs. J Comp Neurol 446: 11-24.

Sandrew BB, Edwards DL, Poletti CE, Foote WE (1986). Amygdalospinal projections in the cat. Brain Res 373: 235-239.

Sato H, Endo K, Ikegami H, Imagawa M, Sasaki M, Uchino Y (1996). Properties of utricular nerve-activated vestibulospinal neurons in cats. Exp Brain Res 112: 197-202.

Sato H, Imagawa M, Isu N, Uchino Y (1997). Properties of saccular nerve-activated vestibulospinal neurons in cats. Exp Brain Res 116: 381-388.

Satoda T, Matsumoto H, Zhou L, Rose PK, Richmond FJ (2002). Mesencephalic projections to the first cervical segment in the cat. Exp Brain Res 144: 397-413. 
Sawchenko PE, Swanson LW (1982). Immunohistochemical identification of neurons in the paraventricular nucleus of the hypothalamus that project to the medulla or to the spinal cord in the rat. J Comp Neurol 205: 260272.

Sbriccoli A, Santarelli M, Carretta D, Pinto F, Granato F, Minciacchi D (1995). Architectural changes of the cortico-spinal system in the dystrophin defective mdx mouse. Neurosci Lett 200: 53-56.

Schwanzel-Fukuda M, Morrell JI, Pfaff DW (1984). Localization of forebrain neurons which project directly to the medulla and spinal cord of the rat by retrograde tracing with wheat germ agglutinin. J Comp Neurol 226: 1 20 .

Shen P, Arnold AP, Micevych PE (1990). Supraspinal projections to the ventromedial lumbar spinal cord in adult male rats. J Comp Neurol 300: 263-272.

Shieh JY, Leong SK, Wong WC (1983). Origin of the rubrospinal tract in neonatal, developing, and mature rats. J Comp Neurol 214: 79-86.

Sirkin DW, Feng AS (1987). Autoradiographic study of descending pathways from the pontine reticular formation and the mesencephalic trigeminal nucleus in the rat. J Comp Neurol 256: 483-493.

Smeets WJ, Timerick SJ (1981). Cells of origin of pathways descending to the spinal cord in two chondrichthyans, the shark Scyliorhinus canicula and the ray Raja clavata. J Comp Neurol 202: 473-491. Smith JC, Morrison DE, Ellenberger HH, Otto MR, Feldman JL (1989). Brainstem projections to the major respiratory neuron populations in the medulla of the cat. J Comp Neurol 281: 69-96.

Song G, Yu Y, Poon CS (2006). Cytoarchitecture of pneumotaxic integration of respiratory and nonrespiratory information in the rat. J Neurosci 26: 300-310.

Stockx EM, Anderson CR, Murphy SM, Cooke IR, Berger PJ (2007). The development of descending projections from the brainstem to the spinal cord in the fetal sheep. BMC Neurosci 8: 40.

Swanson LW (1998). Brain maps: Structure of the rat brain, Second Edition. Elsevier Academic Press, New York.

Takada M (1993). Widespread dopaminergic projections of the subparafascicular thalamic nucleus in the rat. Brain Res Bull 32: 301-309.

ten Donkelaar HJ (1976). Descending pathways from the brain stem to the spinal cord in some reptiles. I. Origin. J Comp Neurol 167: 421-442.

ten Donkelaar HJ, de Boer-van Huizen R, Schouten FT, Eggen SJ (1981). Cells of origin of descending pathways to the spinal cord in the clawed toad (Xenopus laevis). Neurosci 6: 2297-2312.

ten Donkelaar HJ, de Boer-van Huizen R (1982). Observations on the development of descending pathways from the brain stem to the spinal cord in the clawed toad Xenopus laevis. Anat Embryol, 163: 461-473.

Torvik A, Brodal A (1957). The origin of reticulospinal fibers in the cat - an experimental study. Anat Rec 128: 113-137.

Tracey D (2004). Ascending and descending tracts in the spinal cord. In: Paxinos G (ed) The rat nervous system, $3^{\text {rd }}$ edition. Elsevier Academic Press, San Diego: 149-164.

Tsukamoto Y, Yamamoto T, Okado H, Nibu K, Terashima T (2003). Retrograde labeling of mouse spinal descending tracts by a recombinant adenovirus. Arch Histol Cytol 66: 209-220.

van Mier P, ten Donkelaar HJ (1984). Early development of descending pathways from the brain stem to the spinal cord in Xenopus laevis. Anat Embryol, 170: 295-306.

Vanderhorst VG (2005). Nucleus retroambiguus-spinal pathway in the mouse: Localization, gender differences, and effects of estrogen treatment. J Comp Neurol 488: 180-200.

VanderHorst VG, Ulfhake B (2006). The organization of the brainstem and spinal cord of the mouse:

relationships between monoaminergic, cholinergic, and spinal projection systems. J Chem Neuroanat 31: 2-36. Wada N, Sugita S, Jouzaki A, Tokuriki M (1993). Descending projections to coccygeal spinal segments in the cat. J Anat 182:259-265.

Warner G, Watson CR (1972). The rubrospinal tract in a diprotodont marsupial (Trichosurus vulpecula). Brain Res 41: 180-183.

Warren S, Waitzman DM, May PJ (2008). Anatomical evidence for interconnections between the central mesencephalic reticular formation and cervical spinal cord in the cat and macaque. Anat Rec 291: 141-160. Watson C, Harvey AR (2009). Projections from the brain to the spinal cord. In: Watson C, Paxinos G, Kayalioglu G (ed). The spinal cord. Elsevier Academic Press, San Diego: 168-171.

Webster DM, Steeves JD (1988). Origins of brainstem-spinal projections in the duck and goose. J Comp Neurol 273: 573-583.

Webster DM, Steeves JD (1991). Funicular organization of avian brainstem-spinal projections. J Comp Neurol 312: 467-476.

Wild JM, Cabot JB, Cohen DH, Karten HJ (1979). Origin, course and terminations of the rubrospinal tract in the pigeon (Columba livia). J Comp Neurol 187: 639-654.

Xu XM, Martin GF (1989). Developmental plasticity of the rubrospinal tract in the North American opossum. J Comp Neurol 279: 368-381. 
Zemlan FP, Pfaff DW (1979). Topographical organization in medullary reticulospinal systems as demonstrated by the horseradish peroxidase technique. Brain Res 174: 161-166. 


\section{Figure legends}

Fig. 1 In this diagram of a coronal section through the caudal hindbrain, at the level of the rostral pole of the thalamus, labeled neurons are shown in the motor and somatosensory cortical areas. The density of lablled neurons was greater on the contralateral side. Labelled neurons were not present in S1BF and S1ULp. The density of labeling in M1 and M2 was higher than that in S1 (S1HL, S1FL) and S2 (S2 cells were not labeled at this level). A line of labeled neurons was present in STMPL. [In Figures 1-15 labeled cells have been plotted on the diagrams of coronal sections from the mouse brain atlas of Franklin and Paxinos (2008). The interaural (anteroposterior) coordinate is shown on the bottom left]. A photomicrograph of a typical injection site is shown in the bottom right hand corner (its scale bar is 200 micrometers). The photomicrograph in the upper left shows labeled cells in layer 5 of S1FL. The photomicrograph in the upper right shows labeled cells in layers 5 and 6 of M1 and M2. In these and all subsequent photomicrographs, the scale bar represents 50 micrometers

Fig. 2 In this diagram of a coronal section through the caudal hindbrain at the level of the caudal paraventricular nucleus, labeled neurons are shown in M1, M2, S1 (S1HL, S1Sh, S1DZ,), and S2, with a contralateral predominance. Large numbers of neurons were labeled in the paraventricular hypothalamic nucleus, mainly in PaPo. Some neurons were labeled in PLH, TuLH, RChL, and VMH and a few neurons were labeled in CeM. All the hypothalamic and amygdaloid labeling was on the ipsilateral side except for PLH which has bilateral labeling. The photomicrograph on the left shows labeled cells in the PaMP and PaPo. The photomicrograph on the right shows a few labeled cells in the CeM nucleus of the amygdala

Fig. 3 In this diagram of a coronal section through the caudal hindbrain at the level of STh, labeled neurons are shown in contralateral S1Tr and S2. In the hypothalamus, labeled neurons were present ipsilaterally in PLH, MCLH, VMH, and STh. In the prethalamic region, labeled neurons were present in the PaXi and a few labeled neurons were seen in the ipsilateral BLA. The photomicrograph in the upper left shows labeled cells in layer 5 of the trunk region of S1 (S1Tr)

Fig. 4 In this diagram of a coronal section through the caudal hindbrain at the level of the dorsal lateral geniculate nucleus (DLG), labeled neurons are shown in bilateral LH and ipsilateral PH. In the diencephalon, labeled neurons were present in the medial part of PF, SPF and A11 cell group. Labeled neurons were also seen in the ipsilateral $\mathrm{H}$ and ZID. The photomicrograph in the upper right shows labeled cells in PF. The photomicrograph in the middle right shows labeled cells in ZID. The photomicrograph in the lower right shows labeled cells in SPF and the adjacent A11 cell group

Fig. 5 In this diagram of a coronal section through the caudal hindbrain at the level of the medial geniculate nucleus (MG), labeled neurons are shown in InC and Dk on both sides. Labeled neurons were present in the ipsilateral PAG and contralateral MCPC. A few labeled neurons were found in MA3 (ipsilaterally), PrEW (in the midline), and RPC (bilaterally). The photomicrograph in the upper left shows labeled cells in MCPC

Fig. 6 In this diagram of a coronal section through the caudal hindbrain at the level of the interpeduncular nucleus (IP), labeled neurons are shown in RMC, mainly in the ventral portion. Labeled neurons were present in $\mathrm{mRt}$ and RPC bilaterally. Labeled neurons were seen in LPAG and DMPAG on the ipsilateral side. A few labeled neurons were present in InC and Dk. A few labeled neurons were present in parts of the oculomotor complex (Su3C, MA3, EW). A small number of labeled neurons were present in DpG on the contralateral side. The photomicrograph in the upper right shows a small cluster of labeled cells in LPAG. The photomicrograph in the lower left shows large strongly labeled cells RMC

Fig. 7 In this diagram of a coronal section through the caudal hindbrain at the level of the pontine nuclei, labeled neurons are shown in the contralateral PL. In the reticular formation, labeled neurons were present in PnO and $\mathrm{mRt}$ with a contralateral predominance. Labeled neurons were present in the contralateral PTg. Labeled neurons were present in the ipsilateral PrCnF, VLPAG, LPAG, and Su3C. The photomicrograph in the upper right shows labeled cells in PrCnF. The photomicrograph in the lower left shows labeled cells in PL

Fig . 8 In this diagram of a coronal section through the caudal hindbrain at the level of the trochlear nucleus, labeled neurons are shown in the ipsilateral LPAG, VLPAG and adjacent PrCnF. In the reticular formation, labeled neurons were present in $\mathrm{mRt}$ and PnO bilaterally with a contralateral predominance. Labeled neurons were also present in the contralateral PL and ERS. The photomicrograph in the lower right shows large labeled cells in the ipsilateral PnO. The photomicrograph in the lower left shows labeled cells in PL and the adjacent ERS which has smaller neurons than PL 
Fig. 9 In this diagram of a coronal section through the caudal hindbrain at the level of the rostral pole of LC, labeled neurons were mainly present in the ipsilateral MPB, LPB. Labeled neurons were present in bilateral Pr5VL, Su5, SubCD, and SubCV with an ipsilateral predominance. Labeled neurons were present in bilateral $\mathrm{PnC}$ but there were more neurons on the ipsilateral side. The photomicrograph in the lower right shows the band of labeled cells in SubCD and the photomicrograph in the lower left shows labeled cells in SubCV

Fig. 10 In this diagram of a coronal section through the caudal hindbrain at the level of the superior olive, labeled neurons are shown in a number of nuclei in the reticular formation (GiA, PnC, IRt, PCRt, LPGi), with an ipsilateral predominance. The densest group of labeled neurons is seen in the ipsilateral Gi and LPGi. In the raphe, labeled neurons were present in RIP, RMg, and RPa. Labeled neurons were present in the ventral part of Pr5 with an ipsilateral predominance. Labeled neurons were present bilaterally in MVe. Many labeled neurons were present in the ipsilateral Bar and a smaller number of neurons were present in the adjacent LC and SuVe. The photomicrograph in the upper right shows labeled cells in Bar and LC. The photomicrograph in the middle left shows labeled cells in IRt

Fig. 11 In this diagram of a coronal section through the caudal hindbrain at the level of $7 \mathrm{~N}$, labeled neurons are shown in a number of nuclei in the reticular formation (GiA, Gi, IRt, PCRtA, LPGi, DPGi), with an ipsilateral predominance except in DPGi. The densest group of labeled neurons is seen in the ipsilateral GiA and LPGi. Labeled neurons were present in the ventral portion of Sp5O bilaterally. In the raphe, labeled neurons were present in RMg and RPa. Labeled neurons were present in MVe (bilaterally), and in LVe and SuVe (ipsilaterally). Labeled neurons were present in Med and IntA on the contralateral side. The photomicrograph in the upper right shows large strongly labeled cells in LVe. The photomicrograph in the lower right shows two labeled cells in RTz. The photomicrograph in the lower left shows a band of large labeled cells in GiA. The photomicrograph in the upper left shows strongly labeled cells in IntA

Fig. 12 In this diagram of a coronal section through the caudal hindbrain at the level of the rostral part of Amb, labeled neurons are shown in a number of nuclei in the reticular formation (GiV, Gi, IRt, PCRt, LPGi, LPGiE, DPGi), with an ipsilateral predominance except in DPGi. The densest group of labeled neurons is seen in the ipsilateral GiV. Labeled neurons were present in the ventral part of Sp5I bilaterally. In the raphe, labeled neurons were present in RPa. Labeled neurons were present in MVe and SpVe (bilaterally). Labeled neurons were present in Med, MedDL, and IntP on the contralateral side. Labeled neurons were present bilaterally in $\mathrm{Amb}$ and adjacent respiratory nuclei (Bo, RVL) with a contralateral predominance. The photomicrograph in the upper right shows large strongly labeled cells in MVeMC. The photomicrograph in the lower right shows large strongly labeled cells in Gi. The photomicrograph in the lower left shows a cluster of strongly labeled cells in Amb. The photomicrograph in the upper left shows strongly labeled cells in IntP

Fig. 13 In this diagram of a coronal section through the caudal hindbrain at the level of rostral $12 \mathrm{~N}$, labeled neurons were present in bilateral MVe, SpVe, and Sp5I. Labeled neurons were present in a number of subnuclei of the ipsilateral Sol (SolV, SolL, SolM). In the reticular formation, labeled neurons were present in bilateral PCRt, IRt, Gi, GiV, LPGi with an ipsilateral predominance in GiV and LPGi, contralateral dominance in Gi. The densest group was GiV. Labeled neurons were present in bilateral Amb and PrBo with a contralateral predominance. Labeled neurons were present in $\mathrm{ROb}$ and $\mathrm{RPa}$. The photomicrograph in the lower right shows strongly labeled cells in $\mathrm{ROb}$ and adjacent $\mathrm{GiV}$. The photomicrograph in the lower left shows large strongly labeled cells in Sp5I

Fig. 14 In this diagram of a coronal section through the caudal hindbrain at the level of the inferior olivary nucleus (IO), labeled neurons are shown in a number of nuclei in the reticular formation (MdV, MdD, IRt, PMn), with an ipsilateral predominance. Labeled neurons were present in the ventral part of Sp5I bilaterally. Labeled neurons were present bilaterally in Amb and adjacent respiratory nuclei (RVRG) with a contralateral predominance. Labeled neurons were present in a number of subnuclei of Sol (SolL and SolV). A small number of neurons were present in $\mathrm{Cu}$. The photomicrograph in the upper right shows labeled cells in $\mathrm{Cu}$. The photomicrograph in the lower right shows large strongly labeled cells in MdD. The photomicrograph in the lower left shows smaller labeled cells in PMn and larger labeled cells in MdV

Fig. 15 In this diagram of a coronal section through the caudal hindbrain at the level of the pyramidal decussation (pyx), labeled neurons are shown in a number of nuclei in the reticular formation (MdV, MdD, IRt), with an ipsilateral predominance. Labeled neurons were present in the dorsal portion of Sp5C bilaterally. Labeled neurons were present contralaterally in RAmb. Labeled neurons were present in a number of subnuclei of Sol (SolC, SolM). A small number of neurons were present in the ventral part of $\mathrm{Cu}$ and $\mathrm{Gr}$. The 
photomicrograph in the lower right shows a large number of labeled cells in IRt. The photomicrograph in the lower left shows a cluster of strongly labeled cells in RAmb

Fig. 16 In this diagram of a sagittal section close to the midline, labeled neurons are seen in the hindbrain, cerebellum, midbrain, diencephalon, hypothalamus and cerebral cortex. In the hindbrain reticular formation, labeled cells are present in PnC, Gi, LPGi, GiV, IRt, and MdV. In the dorsal part of the hindbrain, labeled cells are present in Bar, MVe, Sol, and rostral $\mathrm{Cu}$. In the cerebellum, labeled cells are present in Med. In the midbrain, labeled cells are concentrated in the red nucleus (RMC, RPC), mRt, and the PAG (DLPAG). In the diencephalon, labeled neurons are present in PCom, MCPC, PF, RPF, H. In the hypothalamus, labeled neurons are present in the perifornical part of lateral hypothalamus (PeFLH), VMH, RChL, PaPo. In the cerebral cortex, labeled neurons are present in M2. The photomicrograph in the upper right shows labeled cells in Med. The photomicrograph in the lower right shows large strongly labeled cells in PnC. The photomicrograph in the lower left shows a cluster of small labeled cells in $\mathrm{PaPo}$

Fig. 17 In this diagram of a sagittal section lateral to the mammillothalamic tract (mt), labeled neurons are seen in the hindbrain, cerebellum, midbrain, diencephalon, hypothalamus and cerebral cortex. In the hindbrain reticular formation, densely labeled neurons are present in SubCD, SubCV, MdD, MdV, and LPGi; less densely labeled neurons are present in PCRt, IRt, PnO. In the dorsal part of the hindbrain, densely labeled neurons are present in MVeMC and caudal SpVe; less densely labeled neurons are present in PTg, MPB, LC, MVePC, caudal Sol, and rostral $\mathrm{Cu}$. In the cerebellum, labeled neurons are present in MedDL, IntA, and IntP. In the midbrain, labeled cells are concentrated in RMC. Labeled neurons are also present in mRt, DpWh, PrCnF. In the diencephalon, labeled neurons are seen in H. In the hypothalamus, labeled neurons are present in LH (PeFLH, PLH). In the cerebral cortex, labeled neurons are present in both M1 and M2. The photomicrograph in the upper right shows a cluster of strongly labeled cells in caudal $\mathrm{SpVe}$. The photomicrograph in the upper left shows a stripe of labeled cells in mRt and PrCnF. The photomicrograph in the lower left shows large strongly labeled cells in RMC

Fig. 18 In this diagram of a sagittal section at the lateral edge of SC, labeled neurons are seen in the hindbrain, cerebellum, midbrain, diencephalon, extended amygdala, and cerebral cortex. In the hindbrain, labeled neurons are present in the ventral portion of Pr5, Sp5O, and Sp5I and in the dorsal portion of Sp5C. A few labeled neurons are present in RVL and PCRtA. In the dorsal hindbrain, labeled neurons are present in SuVe, LVe, $\mathrm{MVe}$, and SpVe. In the rostral hindbrain, a large number of labeled neurons are present in PL. A few labeled neurons are also present in KF. In the cerebellum, labeled neurons are present in both IntA and IntP. In the midbrain, a few labeled cells are present $\mathrm{mRt}$. In the diencephalon, a number of neurons are present in ZID. In the amygdala, a small number of labeled neurons are present in the extended amygdala (EA). In the cerebral cortex, a large number of labeld neurons are present in M1, S1HL, S1Sh, S1Tr. The photomicrograph in the upper right shows large strongly labeled cells in $\mathrm{SpVe}$. The photomicrograph in the lower right shows a stripe of labeled cells in PL and adjacent KF. The photomicrograph in the lower left shows a band of strongly labeled cells in ZID 